\title{
Contribuições para a Avaliação Psicológica e Neuropsicológica
}

\author{
Femanda Luzia Lqpes- UnivesidadeSãoFramiso, Itatiba, SãoPaulo, Brasil
}

Hutz, C. S. (O rg.). (2012). Avançs emA valiaçãoPsicdógia eNerropsiclóg்a deCriançaseAddesentes II. São Paulo: Casa do Psicólogo.

A profissão de psicólogo, neste ano de 2012, comemora 50 anos de sua regulamentação. Desde então, o desenvolvimento das áreas correlatas à ciência psicológica, dentre elas a Avaliação Psicológica, segue em grande efervescência e contribui não somente para esta área como disciplina e campo de estudos, mas para 0 arcabouço teórico e prático de profissionais preocupados com a qualidade dos instrumentos de avaliação utilizados em sua prática. Dentre os critérios de qualidade desses instrumentos de medida psicológica, é importante conhecer as ferramentas necessárias ao seu processo de construção, desde a correta definição do construto até os estudos que permitam verificar sua eficiência. Tendo em vista essa preocupação, Claudio Simon Hutz organizou 0 segundo volume do livro Avançs emavaliaçãopsicoógica e narcpsicdóġa decrianças eaddescentes II, dividido em 19 capítulos, que conta com o auxílio de profissionais com experiência, pesquisas e publicações pertinentes à Avaliação Psicológica.

O primeiro capítulo do livro, de autoria de Felipe Valentini e Jacob Arie Laros, "Métodos atuais de estatística aplicada e psicometria", tem por objetivo familiarizar 0 leitor às possíveis técnicas estatísticas utilizadas na prática e na pesquisa em avaliação psicológica. Esse capítulo abarca desde os conceitos estatísticos básicos até os modelos avançados utilizados em psicologia, como a análise de regressão, análise fatorial exploratória e confirmatória, além da Teoria de Resposta ao Item.

Alessandra Gotuzo Seabra, Elizeu Coutinho de Macedo e Fernando César Capovilla são os autores do segundo capítulo, intitulado "Avaliação neuropsicológica", e proporcionam uma sucinta definição acerca da neuropsicologia, seu histórico, sua importância e suas influências. Também relatam os objetivos, implicações e características dessas avaliações e, ainda, os aspectos a serem considerados na avaliação neuropsicológica infantil.

O terceiro capítulo expõe a "Avaliação da atenção", sob a autoria de Luiz Renato Rodrigues Carreiro e Maria Cristina Triguero Veloz Teixeira. 0 capítulo permite ao leitor a compreensão dos conceitos, dos efeitos, do desenvolvimento e dos tipos e classificações do construto Atenção, dando enfoque para as bases neurais dos processos atencionais e os métodos de estudo da atenção. Os autores discutem a utilização e o desenvolvimento de testes na avaliação da atenção e descrevem um estudo de caso que auxilia na compreensão do tema abordado e suas implicações ao contexto.

"Linguagem oral" é o título do quarto capítulo proposto por Caroline Tozzi Reppold, Léia Gonçalves Gurgel, Ana Cristina Pedron e Maria Cristina Rodrigues Azevedo Joly. As autoras contextualizam o conceito, a função e as bases neuroanatomofisiológicas da linguagem oral, além de apresentarem os instrumentos de avaliação da linguagem utilizados tanto em crianças como em adultos. Um estudo de caso é apresentado ao fim do capítulo, no qual descreve a avaliação da linguagem oral no contexto infantil.

Com o intuito de expor os variados instrumentos que se propõem à avaliação da linguagem escrita e instrumentos que investigam as habilidades metalinguísticas, Alessandra Gotuzo Seabra, Maria Cristina Rodrigues Azevedo Joly, Carla Alexandra Moita Minervino e Monilly Ramos Araujo Melo, apresentam o capítulo de número cinco, "Avaliação neuropsicológica da leitura". As autoras também relatam a carência de instrumentos que atendam aos critérios de precisão, normatização e validação para 0 contexto da avaliação neuropsicológica e denotam a importância da promoção do desenvolvimento desta área.

Caroline Tozzi Reppold, Clarissa Marceli Trentini e Ana Cristina Pedron definem as funções executivas e sua importância para a neuropsicologia contemporânea no sexto capítulo sob o título "Regendo a orquestra: funções executivas". São conceituadas, pelas autoras componentes, as funções executivas, a saber, memória de trabalho, atenção seletiva e controle inibitório, planejamento, seleção de determinadas ações e flexibilidade cognitiva, componentes das funções executivas. Além disso, são contempladas nesse capítulo, as técnicas de avalição das funções executivas, finalizando com a apresentação de um estudo de caso para melhor ilustrar os conteúdos propostos no capítulo.

O capítulo de número sete, "Avaliação das habilidades visoespaciais", proposto por Maria Cristina Rodrigues Azevedo Joly, Diego Vinícius da Silva e Alessandra Gotuzo Seabra, tem por objetivo inserir 0 
leitor à temática das habilidades visoespaciais e às pesquisas na área. Os autores proporcionam um breve histórico da Teoria das Capacidades Cognitivas de Cattell-Horn-Carroll (CHC), focando a capacidade cognitiva de processamento visual, que engloba as habilidades visoespaciais, cujos estudos na área podem ter expressiva contribuição para 0 conjuntura educacional.

O oitavo capítulo, intitulado "Avaliação neuropsicológica da memória", de Simone Freitas Fuso e Camila Cruz-Rodriguez, apresenta 0 construto memória, seus sistemas e fatores moduladores. Também nesse capítulo, o leitor encontra informações sobre os instrumentos de avaliação da memória utilizados em crianças e em adolescentes, além dos utilizados em adultos e idosos. D escreve, também, dois estudos de caso que evidenciam situações de avaliação em crianças e em idosos.

Juliane Callegaro Borsa, Maycoln Teodoro, Adriana de Andrade Gaião e Barbosa e Luciana Karine de Souza são autores do nono capítulo, intitulado "Avaliação da capacidade de adaptação da infância e na adolescência". Nesse capítulo são apresentados instrumentos de avaliação que buscam investigar 0 estresse na infância e na adolescência, autopercepção, regulação emocional e inibição de comportamentos no processo de adaptação, destacando a importância desses instrumentos em processos psicodiagnósticos de crianças e de adolescentes.

A relevância da família no processo desenvolvimental de crianças e de adolescentes foi relatada no décimo capítulo, intitulado "Avaliação das relações familiares e do comportamento interpessoal de crianças e de adolescentes", de autoria de Janaína Thais Barbosa Pacheco, Luciana Karine de Souza e Maycoln Teodoro. Os autores promovem uma breve discussão de instrumentos de avaliação psicológica que objetivam avaliar o comportamento de crianças e de adolescentes e suas relações familiares.

Maiana Farias Oliveira Nunes, Juliane Callegaro Borsa, Carlos Henrique Sancineto da Silva Nunes e Adriana de Andrade Gaião e Barbosa são autores do capítulo intitulado "Avaliação da personalidade em crianças e adolescentes: possibilidades no contexto brasileiro". Nesse capítulo são abordadas as possíveis perspectivas no estudo da personalidade e os autores discorrem acerca dos instrumentos, com base no Modelo dos Cinco Grandes Fatores da Personalidade e, ainda, instrumentos projetivos de avaliação utilizados no país.

O tema superdotação é citado por Tatiana de Cássia Nakano e Luciana Gurgel Guida Siqueira no capítulo intitulado "Superdotação: modelos teóricos e avaliação". As autoras abordam, nesse capítulo, desde a conceituação do termo superdotação, sua multidimensionalidade e seus modelos teóricos, até 0 processo de identificação e avaliação da superdotação, destacando a importância em promover 0 desenvolvimento de estudos e pesquisas, ainda carentes nessa área.

Estudos com amostras brasileiras da Escala de Inteligência Wechsler para crianças são apresentados por Ana Paula Porto Noronha, Acácia Aparecida Angeli dos Santos, Fabián Javier Marin Rueda e Fermino Fernandes Sisto no capítulo "Estudos brasileiros com a Escala Wechsler para crianças, $4^{\text {a }}$ Edição (WISC-IV)". Esses estudos tiveram por objetivo expor as propriedades psicométricas, mais especificamente, as evidências de validade da WISC-IV.

No décimo quarto capítulo, de autoria de Tatiana de Cássia Nakano e Solange Muglia Wechsler, intitulado "Criatividade: definições, modelos e formas de avaliação", os autores trazem a definição e os modelos de compreensão do construto criatividade, os aspectos considerados na avaliação da criatividade por figuras e palavras, pelos estilos de pensar e criar; além de considerações sobre o Teste de Criatividade Figural Infantil.

"As relações de afetos positivos e negativos com personalidade, esperança, autoestima e satisfação de vida" é o título do capítulo proposto por Cristian Zanon e Claudio Simon Hutz. Este abarca um levantamento das definições do bem-estar subjetivo e suas dimensões compreendidas em afetos positivos e afetos negativos, focos de interesse da recente Psicologia Positiva, além de investigar as possíveis associações dessas variáveis com 0 construto personalidade.

Luiz Pasquali e Cristiane Faiad são os autores do capítulo intitulado "Teste Não-verbal de Raciocínio Infantil (TNVRI)". Neste é possível compreender 0 processo de construção do TNVRI, desde a fundamentação teórica, com a conceituação do construto, até os estudos psicométricos realizados com o teste, que objetivaram buscar evidências de validade e precisão.

Com o intuito de apresentar os estudos de precisão, validade e normatização da Escala de Inteligência Wechsler Abreviada (WAIS), Clarissa Marceli Trentini, Denise Balem Yates e Vanessa Stumpf Heck propuseram o capítulo sob o título "Aplicações da Escala de Inteligência Wechsler Abreviada (WAIS) para a realidade brasileira". O capítulo descreve estudos que indicam as propriedades psicométricas da WAIS considerando uma amostra da população brasileira.

"Teste de Criatividade Figural Infantil" é 0 capítulo de autoria de Tatiana de Cássia Nakano. Nesse 
capítulo a autora apresenta a teoria que fundamenta 0 teste, a descrição e os objetivos do mesmo, bem como os estudos psicométricos que indicam a segurança de seu uso, haja vista que esses estudos mostram evidências positivas de validade e precisão, sendo esses, critérios essenciais para a boa qualidade dos instrumentos psicológicos.

O último capítulo, intitulado "Teste de Desempenho Escolar", de Talita Fernanda da Silva, Carolina Rosa Campos e Tatiana de Cássia Nakano, apresenta o Teste de Desempenho Escolar. O capítulo contempla os objetivos do teste, com a devida descriçãa e seus estudos psicométricos, também destacando a utilização do teste em questão como parte integrante de uma avaliação mais ampla.
Esse livro, organizado por Claudio Simon Hutz, é uma obra baseada nos estudos do Grupo de Trabalho (GT) em Avaliação Psicológica de Crianças e Adolescentes, que tem por objetivo privilegiar 0 desenvolvimento de métodos, técnicas e instrumentos de avaliação psicológica e neuropsicológica, consonantes com os critérios estabelecidos para a qualidade piscométrica dos testes. Sendo assim, esse trabalho proporciona uma grande fonte de informação atualizada sobre os estudos e pesquisas desenvolvidos em Avaliação Psicológica e estende sua contribuição aos profissionais da área e aos futuros psicólogos e neuropsicólogos.

Sobre a autora:

Femanda Luzia Lopes é psicóloga, mestre e doutoranda em Psicologia pelo Programa de Pós-G raduação Strico Sensuem Psicologia da Universidade São Francisco, bolsista do O bservatório da Educação/ CAPES/ INEP.

Contato com a autora:

Rua Antonio Alves, 05 - Centro - CEP 13250-030 - Itatiba-SP, Brasil.

E-mail: fernandallopes@ hotmail.com 